\title{
PH90
}

\section{Tendencias del uso de las tecnologías móviles en espacios urbanos: m-learning y patrimonio cultural}

Irina Grevtsova | Grupo Dhigecs, Universidad de Barcelona

URL de la contribución <www.iaph.es/revistaph/index.php/revistaph/article/view/3695>

\section{RESUMEN}

El presente artículo presenta el estudio de las tendencias del uso de las tecnologías móviles en ciudades con fines educativos y divulgativos sobre el patrimonio urbano. El principal objetivo de la investigación es identificar, analizar y clasificar los principales tipos de aplicaciones creadas para la didáctica y difusión del patrimonio urbano.

Las tipologías de las estrategias de las tecnologías móviles que se presentan han sido definidas según dos criterios fundamentales. El primer criterio que se ha tenido en cuenta es el grado de interactividad entre el usuario y el espacio que se intenta interpretar y de los propios usuarios entre sí. En estos casos, la experiencia del usuario in situ y el tipo de interacción en los espacios urbanos son factores decisivos. Otro criterio que se ha tenido en cuenta, en la participación del desarrollo de las estrategias, ha sido el factor de los roles sociales.

En función de dichos criterios ha sido establecida una tipología tripartita de las estrategias estudiadas, las cuales se definen a partir de tres verbos: informar, jugar y construir. A continuación, se presenta una detallada descripción de cada categoría que se ilustra con varios ejemplos. El estudio finaliza con unas conclusiones sobre la problemática de tres categorías y sus posibles líneas de desarrollo futuro.

\section{Palabras clave}

Aplicaciones informáticas (app) | Ciudades | Educación | Patrimonio cultural | Tecnologías móviles | Turismo | 


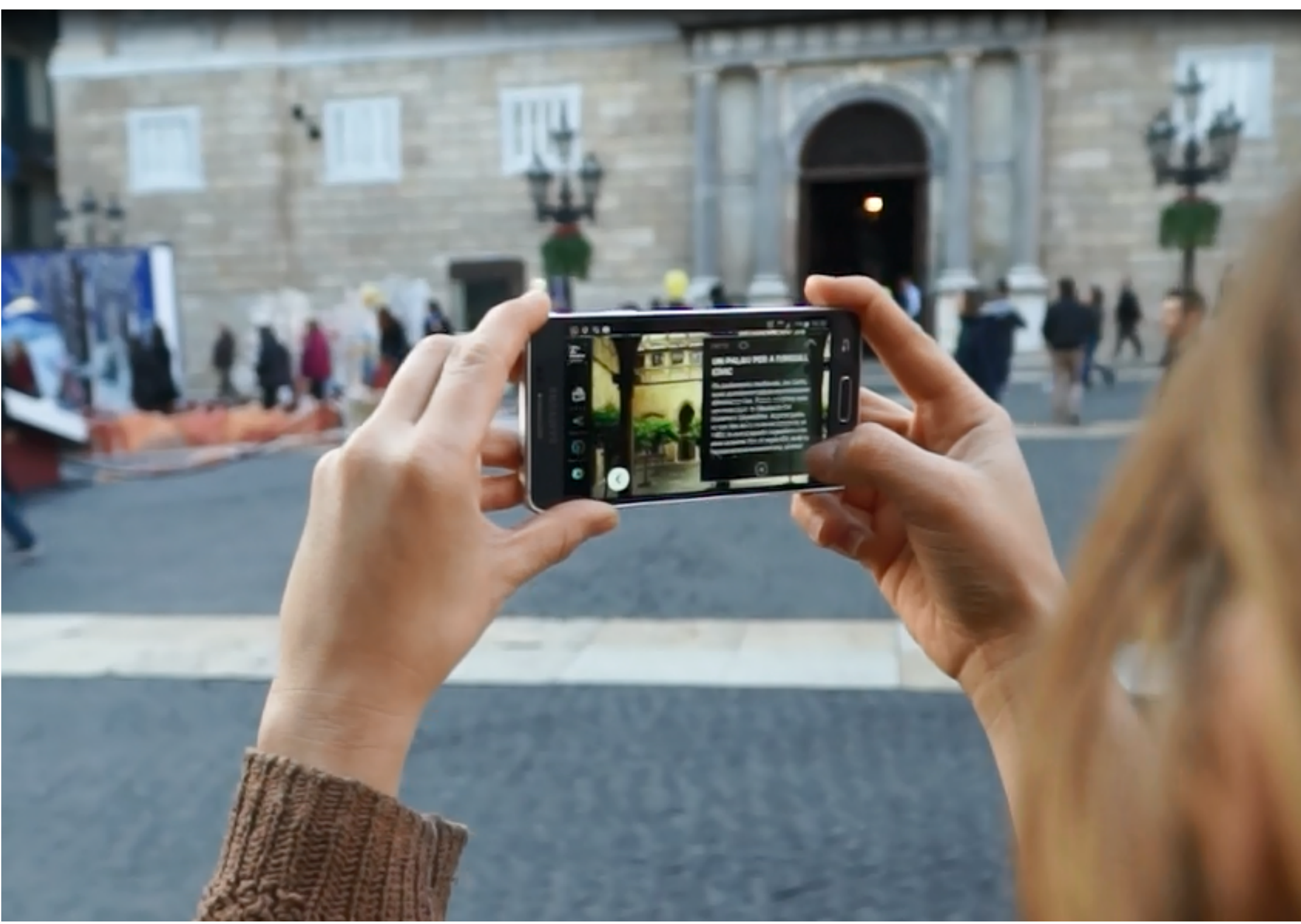

Nuevas formas de interacción educativa y lúdica en espacios urbanos | foto Irina Grevtsova 


\section{INTRODUCCIÓN}

1

El presente estudio se realizó en marco de la tesis doctoral de Irina Grevtsova, dirigida por Joan Santacana y Laia Coma, y titulada Interpretación del patrimonio urbano. Una propuesta didáctica para un contexto histórico mediante las aplicaciones de telefonía móvil. Acceso al texto completo en: http://www.tdx. cat/handle/10803/347215.
En las últimas décadas se han abierto nuevas líneas de estudio y desarrollo de las actividades de la enseñanza y el aprendizaje en la educación. Mobile learning ( $m$-learning) es como se denomina a la nueva modalidad y metodología de aprendizaje con el uso de los medios móviles ${ }^{1}$. M-learning ha crecido como una extensión de la línea e-learning y ha sido aplicada en campos y proyectos diversos, realizados en escuelas, lugares de trabajo, museos, ciudades y zonas rurales de todo el mundo (SHARPLES, 2006; BRAZUELO; GALLEGO, 2011). Aunque este campo ha sido objetos de múltiples estudios por profesionales desde disciplinas distintas, este concepto está todavía en construcción (LÓPEZ BENITO, 2014). Algunas de las características que distinguen el $m$-learning de otras formas de aprendizaje son: la personalización, la adaptación, el compromiso, la autoevaluación, la reflexión por parte del usuario (STEAD, 2006); la exploración de un entorno físico, el aprendizaje en el lugar, el control sobre el proceso de aprendizaje, la discusión con los compañeros, la captura de datos a través de sonido, las imágenes y texto, el aprendizaje basado en la reflexión y los comentarios utilizando productos de conocimiento compartido (LAURILLARD, 2007). Acerca de los cambios que implica el uso de la telefonía móvil, desde el campo formal, han reflexionado diversos autores (SHARPLES, TAYLOR; VAVOULA, 2005; SHARPLES, 2006; SHARPLES et ál., 2009; BRAZUELO; GALLEGO, 2011; SHARPLES et ál., 2013). Asimismo existen estudios, no referidos a la movilidad espacial sino a otro tipo de factores, que se refieren al aprendizaje permanente en cualquier momento y lugar, pero también en cualquier contexto social (VICENT, 2013).

La primera lectura de los beneficios que aportan los smartphones frente a otros medios móviles es múltiple. Entre ellos podríamos citar la movilidad, la comodidad de la visita, la inmediatez de consulta, la información, la interactividad, etc. Sin embargo, en la práctica, se hace evidente que la tecnología no siempre llega a cumplir las necesidades para ofrecer una experiencia enriquecedora. Problemas como el corto funcionamiento de la batería, la dificultad de descarga de datos, la debilidad de la señal y el posicionamiento con GPS en espacios abiertos limitan la experiencia en sitios patrimoniales.

En los últimos años se han introducido en los museos aplicaciones de muchos tipos: gran parte de ellas tienen un carácter informativo, otras son interactivas y de carácter lúdico, y algunas permiten al usuario generar contenidos (LÓPEZ BENITO, 2014). Por otra parte, hay un uso destacado de los conocidos marcadores digitales, entre los que se encuentran los códigos QR, los iBeacons o la tecnología NFC (SANTACANA; COMA, 2014; DAVIES, 2014). Un recurso empleado de manera muy extendida entre los museos es el uso de redes sociales como Twitter, Instagram o Pinterest y por supuesto Facebook (IBÁÑEZ ETXEBERRIA, 2011; CARDONA; FELIU, 
2013). No debemos olvidar el uso destacado de la realidad aumentada y de la geolocalización en espacios patrimoniales.

En contextos urbanos el uso de los medios móviles para la educación patrimonial presenta múltiples ventajas; la tecnología está favoreciendo el diseño de experiencias en relación a repensar la ciudad (VICENT, 2013). En una ciudad como ningún otro entorno físico, que muestra en vivo la historia de la humanidad tangible e intangible y donde los hechos históricos están tan estrechamente entrelazados y la ubicación de los monumentos patrimoniales es muy a menudo irregular y confusa, las tecnologías de la información ofrecen soluciones simples para almacenar y proporcionar la información de una manera más comprensible. El teléfono móvil como medio didáctico, en comparación con sus predecesores clásicos utilizados en entornos urbanos -paneles y señales informativos- es más eficaz, ya que su capacidad tecnológica permite organizar y simplificar gran cantidad de información en una cierta secuencia proporcional, de fácil y comprensible uso para el usuario (GREVTSOVA, 2012). Los medios móviles no sólo simplifican el flujo de información, sino que también enriquecen el contenido y, gracias a sus funcionalidades interactivas, ofrecen una amplia variedad de fórmulas para el patrimonio cultural.

\section{PRINCIPALES CATEGORÍAS DE LA TECNOLOGÍA MÓVIL}

Los estudios de las estrategias de la tecnología móvil, realizados en los últimos años por los investigadores del patrimonio cultural, han demostrado que gran parte de las aplicaciones (app) creadas en este periodo tiene una estructura y diseño de contenidos muy similar (GREVTSOVA, 2013; LÓPEZ BENITO, 2013; SALLÉS, 2013; VICENT, 2013; IBÁÑEZ ETXEBERRIA et ál., 2014). Gran parte de los productos tienen un carácter informativo y presentan una comunicación muy básica (LÓPEZ BENITO, 2014). La mayoría de las aplicaciones son similares y de baja calidad, por lo que con el paso del tiempo no encuentran ninguna utilidad y evidentemente tienden a desaparecer. Muchas otras aplicaciones proporcionan la información de las colecciones o del lugar a modo de catálogo o de guía. Existen aplicaciones que han sido creadas en formato digital cambiando simplemente de formato las guías y rutas existentes. Lo que ofrecen a los usuarios en todos los casos suele repetirse: un índice de obras, mapas interactivos, agenda, artículos y galerías audiovisuales, un conjunto que en el argot se conoce como GLAM (acrónimo inglés de galerías, bibliotecas, archivos y museos). Generalmente, la estructura también es muy parecida. En primer lugar, el usuario accede a un menú con el contenido clasificado (por temas, objetos, salas, etc.) y en segundo lugar, tiene que seleccionar un elemento de interés que a continuación le permite acceder a diferentes tipos de contenidos (imágenes, audio, video, multimedia). En la mayoría de las estrategias se utilizan recursos pre- 
2

Véase la entrada de P. Sánchez en el blog http://urban360.me, publicada el 08/02/2012: From vacation spots to smart destinations: technology and tourism. QR, apps and augmented reality for cities <http://urban360. me/2012/02/08/this-place-worths-a-visitintelligent-destinations-smart-city-technologytourism-and-city-branding/> [Consulta: 21/07/ 2016].

3

Consúltese el listado de las estrategias analizadas en 53 aplicaciones de ciudades de todo el mundo en el anexo 1.5 de mi tesis doctoral <http://www.tdx.cat/bitstream/ handle/10803/347215/02.\%20IRINA_GREVT SOVA_ANEXO_1.pdf?sequence $=9>$ [Consulta: $21 / 07 / 2016]$. viamente diseñados para otros tipos de medios como un libro de texto, un cartel de la sala de un museo, unos paneles, unas señales o unos planos de espacios abiertos, etc. Utilizan el mismo mensaje, estrategias interpretativas y comunicativas para un medio con características totalmente distintas.

Desde el ámbito del patrimonio cultural, y en paralelo, varios investigadores han ido creando distintos tipos de aplicaciones, basándose en la perspectiva del uso de los recursos digitales, a partir de la llegada de la tecnología de los smartphones.

Así, por ejemplo, Rivero (2012) analiza las tendencias del uso de las aplicaciones $m$-learning en la enseñanza durante las salidas escolares. La autora estudia las aplicaciones desde el punto de vista de actividades y define varias categorías: la app guía, los recursos on line, los códigos QR o BIDI, el geoposicionamiento, los juegos, el geocatching y el crowdsourcing colaborativo. Para cada tipo de tecnología presenta un ejemplo práctico del uso de la tecnología móvil en la educación secundaria.

En otro estudio realizado por Ibáñez Etxeberria y otros (2014), se agrupan todas las tendencias emergentes en tres categorías distintas: aplicaciones (app), códigos QR y realidad aumentada. Los autores dan una descripción detallada de las características de cada tecnología y proporcionan ejemplos prácticos del uso de cada uno. La misma clasificación introduce el autor del blog ${ }^{2}$ que expone los tipos de uso de las tecnologías en el turismo y coincide con las tres categorías ya mencionadas: QR, app y realidad aumentada. Muy parecida categorización ofrece Davies (2014), que desde el análisis de la interpretación del patrimonio digital añade a las tecnologías citadas recursos de iBeacon e iBeaken.

\section{ESTUDIO DE LAS TENDENCIAS DEL USO DE LAS TECNOLOGÍAS MÓVILES EN CIUDADES}

Para crear la presente clasificación nos hemos basado, en el análisis de 53 aplicaciones realizadas en ciudades de todo el mundo ${ }^{3}$. Este análisis nos ha permitido obtener una visión global de las aplicaciones diseñadas para ciudades y establecer una clasificación, en la cual agrupamos diversas aplicaciones según sean las estrategias didácticas.

Las tipologías de las estrategias de la tecnología móvil que presentamos posteriormente han sido definidas según dos criterios fundamentales:

El primer criterio a tener en cuenta es el grado de interactividad entre el usuario y el espacio que se intenta interpretar y de los propios usuarios entre sí. En estos casos, la experiencia del usuario in situ y el tipo de interacción 
en los espacios urbanos son factores decisivos. Por ello podemos decir que el carácter de la visita, por ejemplo, de una ruta temática, puede diferir significativamente según la visita se realice mediante un juego o sin él. Sin juego, la interacción con el entorno es pasiva y el carácter de la aplicación es básicamente informativo; es decir, el usuario debe sucesivamente seguir pasos predefinidos por la app y, en consecuencia, no asume un papel activo. Con juego, la interacción es mucho más dinámica gracias a las reglas del juego que motivan al usuario a hacer su propia investigación por la ciudad.

Otro criterio que se ha tenido en cuenta, en la participación del desarrollo de las estrategias, ha sido el factor de los roles sociales. La mayoría de los proyectos son el resultado de un trabajo previo, realizado por el museo o institución cultural, que elabora un discurso, normalmente académico y lo transfiere a los usuarios. Se trata de unos discursos que van siempre de A a $B$, siendo A la institución y $B$ el público. Este tipo de aplicaciones dominan el mercado. Sin embargo hay otro tipo de aplicaciones, ciertamente minoritarias, en las cuales entre A y B hay direcciones biyectivas, de doble sentido, con lo cual la información, ideas y criterios de los usuarios son la base con la cual se construye el discurso. Se trata de aplicaciones altamente participativas, de construcción colectiva.

En función de los criterios anteriormente citados, hemos establecido una tipología tripartita de las estrategias estudiadas, las cuales se definen a partir de tres verbos: informar, jugar y construir. Las tipologías propuestas no se autoexcluyen, sino más bien todo lo contrario: consideramos que el éxito del proyecto depende de una buena combinación de las diferentes estrategias y de su variedad.

Los proyectos del primer grupo son las que se refieren al verbo informar. La estrategia más utilizada para informar y acercar el valor patrimonial de un

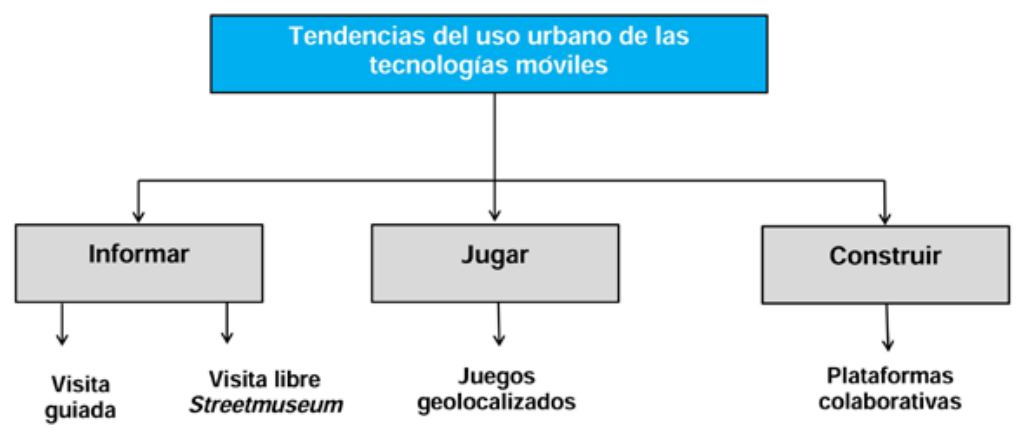


sitio o espacio determinado son las rutas. Actualmente, este tipo de aplicaciones son las más utilizadas. Hay rutas con códigos de realidad aumentada, utilizando imágenes y vídeos con imágenes virtuales, audio y otros contenidos interactivos. Las aplicaciones de esta categoría ofrecen a los usuarios una serie de puntos y lugares de interés, en los que el usuario puede obtener información adicional sobre el objeto. La realización de la ruta puede ocurrir con un programa predeterminado o libremente, teniendo en cuanta las preferencias de los usuarios. Este tipo de aplicaciones presentan la visita guiada clásica de la ciudad, que se puede desarrollar individualmente o en grupo. Hemos destacado dos subcategorías.

La primera categoría presenta una visita clásica, que consiste en un recorrido por una ruta temática y cultural con diferentes puntos de interés. En este tipo de aplicaciones el usuario debe seguir un recorrido lineal según una pauta o una numeración de los POls. La segunda subcategoría de este grupo de aplicaciones también utiliza la ruta para dar a conocer el patrimonio. A diferencia de la categoría anterior los POls no están numerados y se puede visitar el sitio de interés de una forma libre.

Las estrategias del segundo grupo son las que emplean o se definen por el verbo jugar. Se trata casi siempre de juegos lúdicos o educativos. Los usuarios son participantes de un juego en el que deben solucionar tareas, responder preguntas, etc. Se dirigen a diferentes tipos de público: jóvenes, adultos, turistas y público local.

Las estrategias del tercer tipo, se basan en la construcción colectiva de la aplicación. Utilizan estrategias basadas en la participación del público: una forma emergente de conocer y difundir los valores de la ciudad es generando y compartiendo contenidos y experiencias entre usuario e instituciones culturales. Son proyectos que por tener tareas de investigación y de búsqueda de la información se dirigen al público local. La participación en este tipo de proyectos colaborativos puede enriquecer todos los participantes, ya sean de las instituciones museísticas como usuarios.

\section{LAS ESTRATEGIAS DE LAS TECNOLOGÍAS MÓVILES, BASADAS EN EL VERBO INFORMAR. VISITA GUIADA}

Uno de los medios más habituales para conocer una ciudad sigue siendo los itinerarios temáticos diseñados para completar en grupo o individualmente. En el mercado turístico de las ciudades abunda una gran variedad de rutas que pueden encontrarse en guías ya sean de papel ya sean en línea, tanto en las oficinas de turismo como en el mismo lugar de la visita. Este modo de conocimiento y acercamiento al patrimonio urbano es rápido, claro y de fácil ejecución. 
El campo de la tecnología móvil ha dado respuesta a este interés del público, lanzando al mercado un gran número de aplicaciones diseñadas según los criterios establecidos por rutas urbanas. Se pueden encontrar e instalar en el móvil aplicaciones turísticas en casi cualquier ciudad desde las más grandes y más visitadas hasta las poblaciones más pequeñas. Estas aplicaciones corresponden al formato de diseño de una ruta estándar, que incluye un menú con los monumentos más destacados, agrupados por temáticas y con un mapa de indicaciones. Podemos llamar a este tipo de aplicaciones clásicas debido a que son una adaptación directa de las guías de viaje de papel y tienen un bajo coeficiente de innovación.

En las ciudades y en espacios patrimoniales, uno de los principales propósitos de las propuestas basadas en la tecnología móvil es enlazar ideas, conceptos e historias entre distintos elementos patrimoniales, mediante el diseño de un itinerario temático. La ciudad puede contar con una gran variedad de recorridos urbanos: itinerarios abiertos, unidireccionales y multidireccionales, itinerarios priorizados y segmentados, itinerarios temáticos e interactivos (COMA, 2013). Las cadenas de los puntos de interés pueden ser infinitas y su longitud depende, en gran parte, del lugar en el que se realiza la intervención patrimonial. Existen propuestas para todo un centro histórico o para una calle de un barrio, una plaza o, incluso, el perímetro de la ciudad. A continuación presentamos algunos proyectos con estas características.

Uno de los proyectos de este tipo es Relligant Nou Barris que se desarrolló con el apoyo del barrio de Nou Barris de Barcelona. En este caso, los códigos se utilizan para identificar monumentos y unirlos mediante distintas rutas temáticas. Para señalizar monumentos in situ por todo el barrio, se utilizan señales informativas de diseño simple realizadas en madera. En el panel ubicado frente a cada monumento hay un texto descriptivo, una imagen y un código QR que permite ir a la página web del proyecto ${ }^{4}$. Se puede acceder a todos los recursos digitales, desde fotos y vídeos hasta mapas siguiendo distintos criterios. Hay un glosario general, con 21 puntos ordenados alfabéticamente, pero también se puede acceder por categorías, en las cuales los puntos de interés están organizados según siete temas que generan siete itinerarios: las masías; el agua (torrentes, fuentes y acueductos); el inicio del siglo XX; las calles y los barrios; los equipamientos y las luchas; las esculturas y los monumentos y los espacios de culto.

Otro ejemplo del recorrido temático es el proyecto Conoce Moscú. Abarca un área urbana de grandes dimensiones, que ocupa toda la parte central de la ciudad, con multitud de códigos QR instalados, que generan recorridos de gran longitud con más de 15 monumentos. La app Conoce Moscú fue diseñada en mayo de 2013. La aplicación fue desarrollada por el Departamento de Tecnologías de la Información de Moscú junto con el Departamento del Patrimonio Cultural. 
Plano con rutas temáticas de la aplicación Conoce Mosú

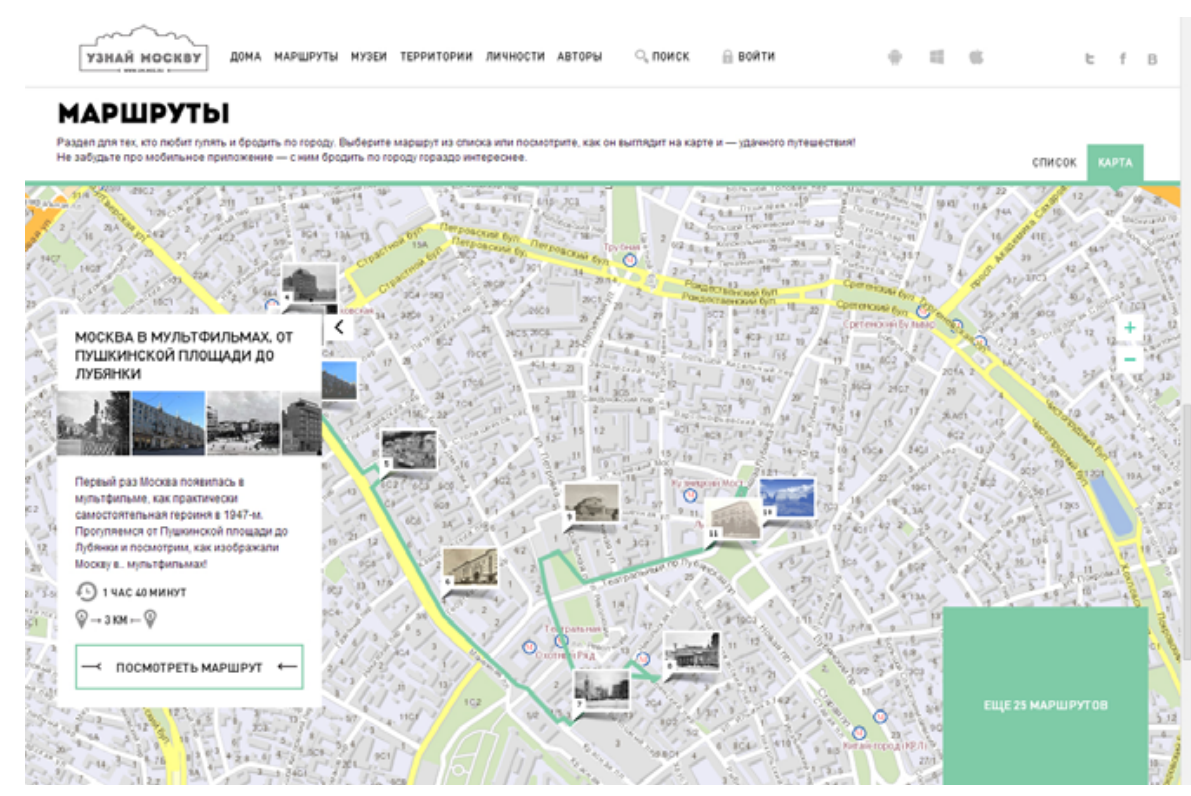

El elemento principal de la interpretación didáctica de este proyecto es una casa. Actualmente, el proyecto cuenta con más de 850 casas ubicadas en todo el centro histórico urbano. Su identificación como elementos patrimoniales de gran importancia histórica, cultural y arquitectónica se hace con la instalación en sus fachadas de paneles con los mencionados códigos QR (GREVTSOVA, 2014).

Una de las pocas propuestas patrimoniales que realiza un especial enfoque en los valores inmateriales de la ciudad es el proyecto Invisible Maps. Fue una iniciativa del Museo DHUB (Museu del Disseny de Barcelona) que se llevó a cabo como un proyecto temporal durante el año 2011. Invisible Maps es un mapa del patrimonio invisible de la ciudad de Barcelona que se crea mediante pequeños fragmentos efímeros de la historia de la propia ciudad. Sus objetivos principales eran hacer visible el patrimonio inmaterial de Barcelona recuperando los recuerdos que permanecían ocultos en la memoria de la gente y motivar la participación de la ciudadanía, destacando los hechos y lugares que han marcado profundamente sus experiencias personales.

En esta propuesta de itinerarios virtuales los códigos QR actúan como un recurso que facilita el acceso a la parte invisible de la ciudad y a su vida intangible expresada en tradiciones, costumbres, fiestas, formas originales de vida y elementos simbólicos. Por un lado, el proyecto busca un diálogo con sus ciudadanos, desarrollando propuestas donde ellos pueden participar activamente y, por otro lado, quiere hacer más comprensible la imagen de la ciudad para sus habitantes. 


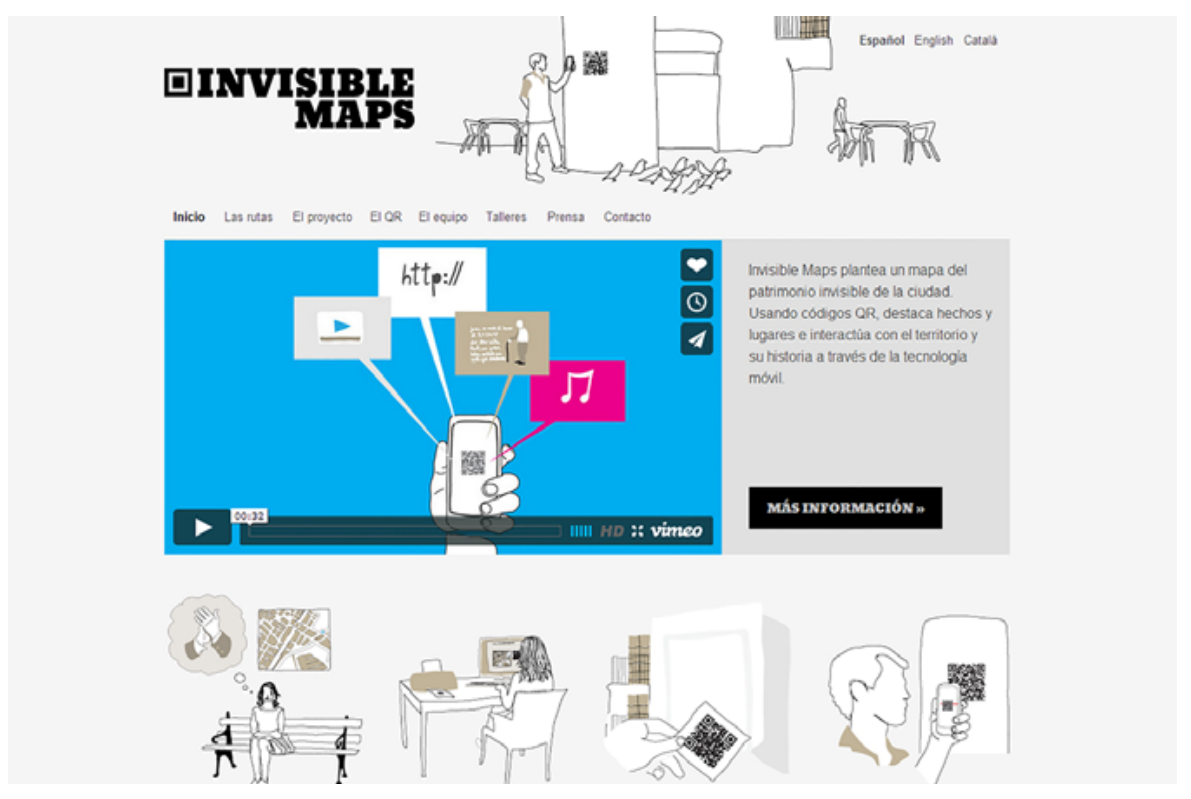

La web del proyecto Invisible Maps

En total, el proyecto incluye 18 propuestas de itinerarios urbanos muy variadas por su temática y número de puntos de interés. Todas las rutas tienen contenidos muy inusuales y distintos a las guías turísticas. Los títulos como "11/11/11@11:11", "Rumba catalana" y "La ciudad y su alfabeto" en seguida llaman la atención por su originalidad. Los temas y elementos de descubrimiento que nos propone esta web son tanto de valor histórico y cultural como objetos banales. Se pueden escoger rutas que cuentan historias de barrios, como "Memorias de la Barceloneta", "Secretos del Borne", que visualizan y observan elementos urbanos de pequeña escala como "Las puertas", o que ofrecen las miradas poco comunes como la ruta "Por encima de los ojos".

\section{LAS ESTRATEGIAS DE LAS TECNOLOGÍAS MÓVILES, BASADAS EN EL VERBO INFORMAR. VISITA LIBRE STREETMUSEUM}

La ciudad guarda una gran parte de su patrimonio que no es visible ni accesible en las calles urbanas. Se trata de las fotografías antiguas, imágenes, grabaciones, películas que se conservan en las estanterías de los archivos municipales, museos e instituciones culturales. Son fuentes históricas que captan imágenes urbanas, vistas de eventos culturales, detalles de edificios y monumentos, acercando la historia a simple vista, de un modo inmediato.

Tradicionalmente este patrimonio documental se ha encuentra en las instituciones culturales y en los grandes archivos públicos en los que el acceso a los fondos ha sido generalmente restringido al público general. Las nuevas tecnologías de la información han cambiado rápidamente este hecho, 
derribando las viejas barreras físicas y sacando los fondos directamente a la calle, a disposición de cualquiera que esté interesado en la historia de la ciudad.

El acceso abierto a los fondos históricos directamente desde los dispositivos móviles y las plataformas portátiles ha dado una nueva oportunidad para presentar y difundir fuentes históricas a nuevas audiencias (MITCHELL; SUCHY, 2012). El móvil se ha convertido no sólo en un medio de comunicación digital y de difusión del patrimonio, sino en una herramienta propia de investigación y estudio de la historia local.

Este cambio ha generado una nueva línea de diseño de las aplicaciones, en el ámbito del patrimonio urbano, que podemos llamar streetmuseum app, que ha ampliado aún más las posibilidades interactivas para la interpretación del patrimonio cultural. La característica principal de este grupo de aplicaciones es el hecho que van más allá del espacio físico del museo y hacen accesibles todas las fuentes documentales, fotográficas, audiovisuales, etc., tradicionalmente encerradas en los archivos y museos. Este tipo de proyectos atraviesan los muros de las instituciones culturales: son aplicaciones en las que el contenido del museo se integra con el espacio urbano generando una simbiosis de carácter marcadamente educativo.

Para ello, utilizan fundamente dos tecnologías. En primer lugar, la ubicación original de una fuente se fija en un mapa con las coordenadas geográficas que permite restablecer la conexión pérdida con el lugar y al mismo tiempo creando una nueva interpretación de la historia, una nueva experiencia, una nueva forma de relacionarse con el entorno. En segundo lugar, el uso de la realidad aumentada que superpone una capa histórica sobre la realidad actual, que permite entrar en la historia y verla directamente en la calle en el contexto actual, lo que fortalece y enriquece la experiencia in situ. La función de visualizar y comparar paisajes urbanos de distintos momentos históricos, permite tomar conciencia de que la ciudad se compone de múltiples capas de información que, gracias a la realidad aumentada, ha sido posible recuperar.

Desde hace algunos años distintas instituciones culturales de todo el mundo han empezado a implementar las aplicaciones y herramientas digitales, como la realidad aumentada y los mapas geolocalizados, para crear proyectos educativos y de difusión de la historia de la ciudad. El primero fue el museo Powerhouse en Sydney, Australia (BOYER; MARCUS, 2011). La institución empezó el desarrollo del proyecto con el diseño en agosto de 2008 de una mashup de las fotografías históricas y añadiendo las herramientas de Google. En la página del museo en Flickr ${ }^{5}$ se pueden localizar las imágenes históricas del museo en el Google Maps y compararlas con las vistas contemporáneas de la ciudad gracias a Google Street View. 
El segundo paso fue el diseño de una aplicación en el año 2009 con el uso de la realidad aumentada Layar para mostrar las imagines históricas de Sydney en las calles de la ciudad ${ }^{6}$. La aplicación permite, al seleccionar un punto de interés en cualquier lugar de la ciudad, acceder a las imágenes superpuestas sobre la realidad y visualizar un mapa. Al hacer clic en un elemento se abre un menú con distintas opciones, incluyendo el enlace a la página web del grupo en Flickr ${ }^{7}$ y direcciones del mapa, con indicaciones para llegar muy cerca del punto en el que la fotografía ha sido geocodificada.

Otra de las iniciativas pioneras de las aplicaciones, que ha tenido más repercusión en el sector museístico y, posteriormente ha sido utilizado como modelo en muchas ciudades, es la aplicación Streetmuseum, creada por el Museo de Londres en el año $2010^{8}$. La aplicación da a conocer el patrimonio fotográfico del museo $\mathrm{y}$, mediante la realidad aumentada, proporciona acceso a cientos de imágenes históricas de Londres. Es un proyecto que no sólo permite visualizar el pasado en las calles y plazas de la ciudad, sino que permite también guardar y compartir experiencias. La aplicación recibió una gran aceptación de los medios, y tuvo más de 50.000 descargas en las primeras semanas.

La idea del uso de las imágenes como fuente para explicar el pasado de la ciudad, mostrar proyectos de edificios, de espacios urbanos en construcción y de los planos urbanísticos del futuro ha sido utilizada en la app creada por el Instituto Holandés de Arquitectura: UAR (Urban Augmented Reality) ${ }^{9}$. UAR App presenta contenidos que están mapeados en un plano, utilizando herramientas digitales interactivas combinadas con la realidad aumentada (HARKEMA; NYGREN, 2012). La UAR fue lanzada el 30 de junio de 2010 y en aquel momento ya disponía de una base de datos muy extensa sobre los

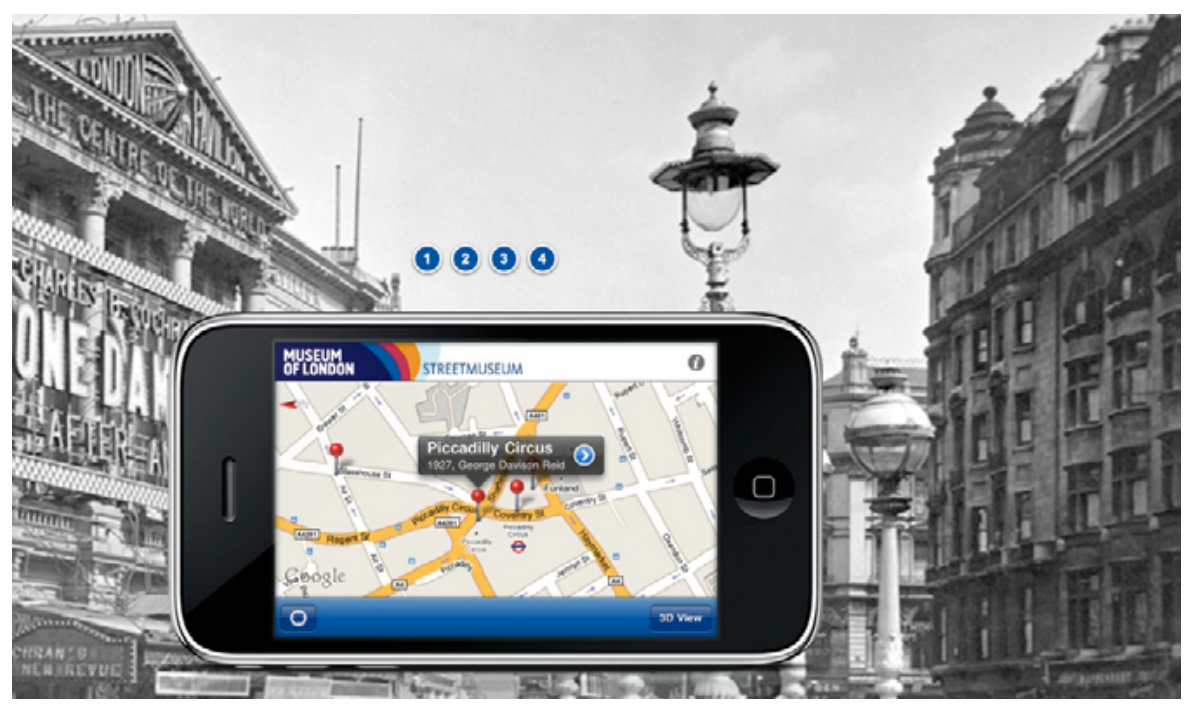

6

<http://www.powerhousemuseum.com/layar/> [Consulta: 15/09/2015].

7

<https://www.flickr.com/photos/powerhouse museum/sets/> [Consulta: 15/09/2015]

8

<http://www.museumoflondon.org.uk/Resour ces/app/you-are-here-app/home.html> [Consul ta: 25/07/2016].

9

<https://itunes.apple.com/us/app/uar/id37145 9375?mt=8> [Consulta: 15/09/2015]. 
El funcionamiento de la app Urban Augmented Reality (UAR)

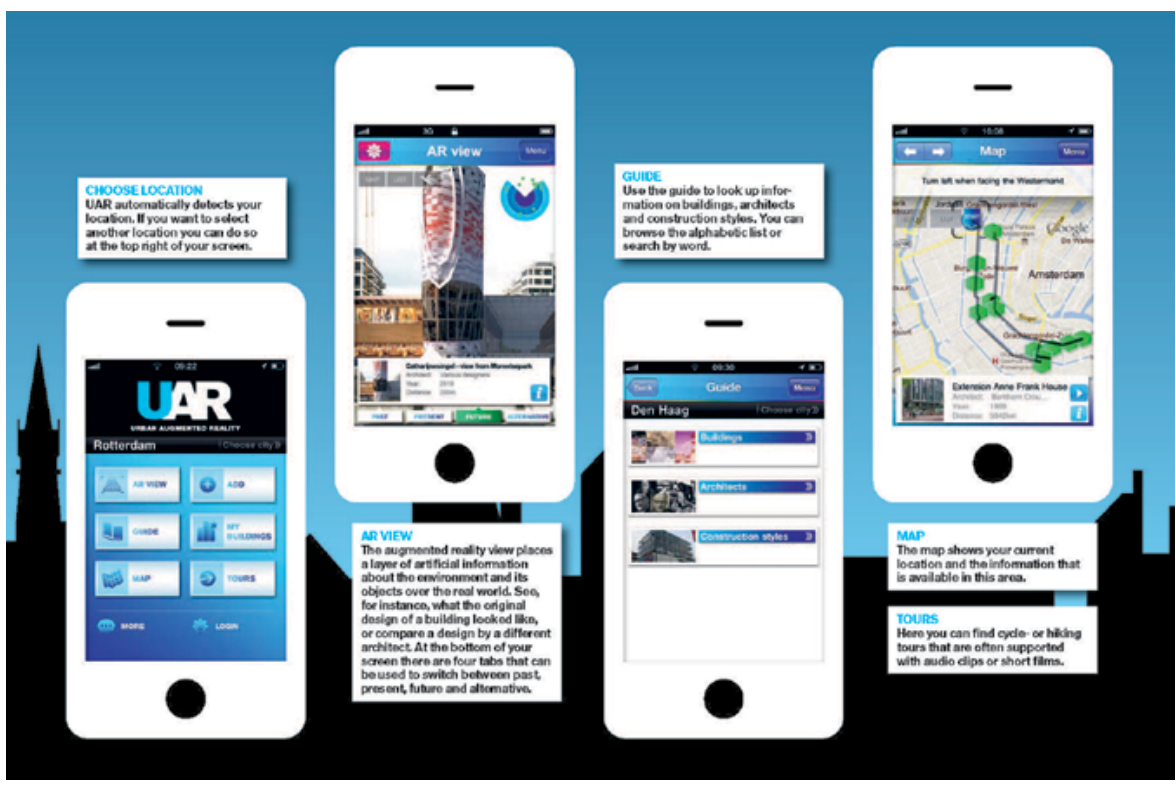

edificios de Rotterdam. Se lanzó con 350 elementos, entre los cuales algunos ya eran en tres dimensiones. En noviembre se hicieron accesibles 450 edificios de Amsterdam y, posteriormente, el proyecto fue creciendo y fue distribuido en otras ciudades de los Países Bajos. UAR es una plataforma colaborativa en la que los usuarios pueden añadir contenidos e información a los edificios. Los usuarios también pueden corregirse la información entre ellos.

El proyecto ha tenido un gran impacto social y gran interés por diferentes grupos y colectivos. En su diseño han colaborado profesionales de campos muy diversos como centros de arquitectura, instituciones de arte, archivos municipales, museos, autoridades locales y agentes del mercado.

\section{LAS ESTRATEGIAS DE LAS TECNOLOGÍAS MÓVILES, BASADAS EN EL VERBO JUGAR (JUEGOS GEOLOCALIZADOS)}

Una forma emergente de utilizar las nuevas tecnologías $m$-learning en contextos urbanos es crear actividades lúdicas y educativas a base de distintos tipos de juegos, utilizando métodos y técnicas de los juegos tradicionales, generalmente conocidos como juegos urbanos o juegos de calle (AVOURIS; YIANNOUTSOU, 2012).

Durante los últimos años se han presentado propuestas para medios móviles, cuya principal característica ha sido desarrollar juegos que evolucionan según la ubicación de los jugadores (AVOURIS; YIANNOUTSOU, 2012). 
Un término propuesto para describir este tipo de juegos es location-based games (LBG) que se puede traducir como juegos geolocalizados. Su llegada se debe a la generalización del uso de dispositivos móviles, como teléfonos inteligentes y tablets, con avanzadas funcionalidades de ubicación y la capacidad de detección del GPS de posicionamiento por satélite. El acceso a la red de dispositivos móviles rompe la tradición de jugar solo en un lugar físico y permite la fusión de la tecnología digital por todo el espacio urbano (SINTORIS et ál., 2013).

Las actividades lúdico-didácticas que se desarrollan en la ciudad convierten un contexto urbano en un tablero de juego. El potencial educativo que tienen los lugares patrimoniales de las ciudades y el carácter lúdico de los juegos, basados en la localización, enriquecen la experiencia de los visitantes y proporcionan nuevas fórmulas de aprendizaje. Se adquiere el conocimiento contextual, que está relacionado con los lugares donde el juego tiene lugar, y se desarrolla mediante el movimiento y la actuación en espacios patrimoniales urbanos auténticos (LÓPEZ; MARTíNEZ; GREVTSOVA, 2015).

Uno de ejemplos es la aplicación Edinburgh-World Heritage City ${ }^{10}$. Este proyecto cuenta con cuatro recorridos por la ciudad de Edimburgo utilizando mapas e imágenes de alta resolución con zoom. Es un juego de exploración que tiene métricas que miden los logros de los diferentes equipos. Al mismo tiempo, la app permite agregar comentarios y fotos de los usuarios y compartirlas con los amigos. Para crear experiencias interactivas se utiliza audio, que da vida a los edificios contando historias sobre los residentes y su pasado.

Otro proyecto, Frequency 1550, es un programa educativo desarrollado gracias a la colaboración Waag Society, 7scenes, KPN, IVLOS (University of Utrecht) e ILO (University of Amsterdam) ${ }^{11}$ para estudiantes de la Montessori Comprehensive School of Amsterdam. Consiste en un juego sobre el centro histórico de Ámsterdam con el uso de los smartphones. La aplicación, mediante diversas preguntas y tareas que los jugadores deben responder y realizar, motiva a los estudiantes a recorrer áreas específicas de la ciudad medieval del 1550. Los participantes deben demostrar sus conocimientos sobre la historia de la ciudad cumpliendo diversas tareas de localización, mediante el GPS.

Para ello, los jugadores deben desplazarse a lo largo de las seis áreas urbanas indicadas y descubrir la historia de la ciudad mediante los puntos de interés. Cada una de las seis áreas urbanas está relacionada con un tema específico: trabajo, comercio, religión, leyes y gobierno, conocimiento y defensa. Una de las partes fuertes del proyecto es el carácter colaborativo de la aplicación. El juego se realiza en grupos. Cada equipo de jugadores tiene tareas que cumplir según su tema o localización.

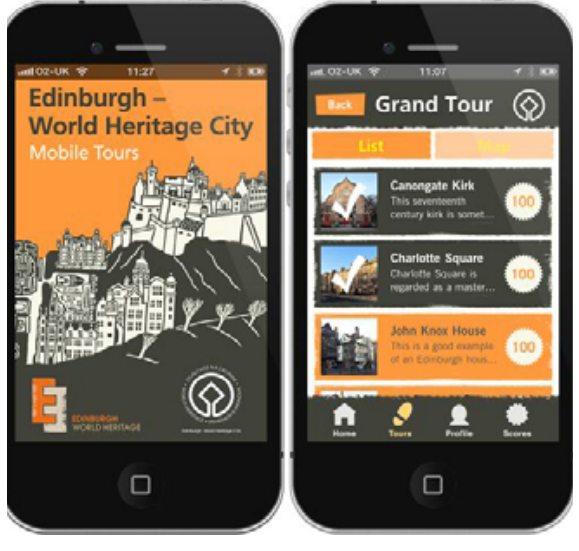

Edinburgh-World Heritage City

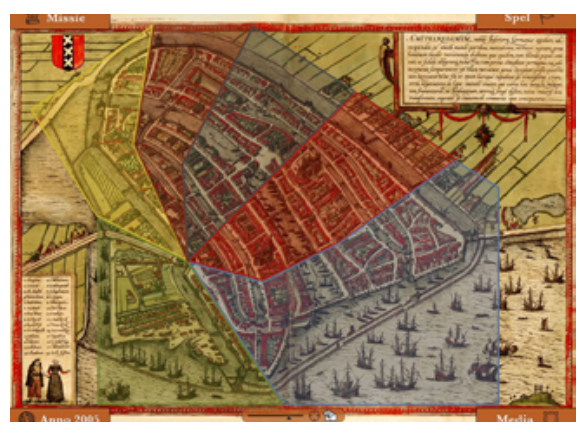

Plano del proyecto Frequency 1550

10

$<$ http://www.ewht.org.uk/visit/edinburgh---worldheritage-city-app> [Consulta: 15/09/2015].

11

<http://7scenes.com/projects/frequency-1550/> [Consulta: 15/09/2015]. 


\section{LAS ESTRATEGIAS DE LAS TECNOLOGÍAS MÓVILES, BASADAS EN EL VERBO CONSTRUIR. PLATAFORMAS COLABORATIVAS}

Otro cambio importante que llevaron a cabo los medios móviles a las ciudades, es el rápido desarrollo y crecimiento global del uso de las redes sociales, lo que ha creado una nueva dirección llamada participatory culture (cultura participativa). Las tecnologías no sólo dan acceso a la información, sino que permiten compartir toda la experiencia, tanto con los grupos más cercanos, como con otros públicos desconocidos y potencialmente masivos. La posibilidad de compartir experiencias, ideas y contenidos a través de los dispositivos móviles y las redes sociales ha cambiado las formas de conocer y percibir las ciudades, modificando para siempre la experiencia y el significado de las visitas culturales (VAN DIJK, 2011).

Las estrategias que utilizan crowdsourcing y redes sociales son una buena manera de crear un espacio común y cómodo para el intercambio y la comunicación entre los museos y el público. El almacenamiento y la divulgación del conocimiento histórico de los residentes y la posibilidad de compartirlo con la sociedad permiten establecer conexiones culturales a diversos niveles, creando un amplio campo en el que cada usuario puede escoger la historia que le interesa.

La mayoría de las iniciativas que se basan en los principios de crowdsourcing han nacido en museos y organizaciones culturales y están dirigidos, por un lado, a aumentar el interés de la población local y su participación en la vida del museo y, por otro, a crear un material original para los turistas y visitantes de la ciudad.

En las ciudades, los proyectos crowdsourcing tienen como finalidad la creación de plataformas colaborativas y abiertas digitales para hacer intercambios de información sobre la historia de la ciudad (SANTACANA MESTRE; LÓPEZ BENITO, 2014: 115). En estos tipos de proyectos gran parte de las iniciativas que toman los museos buscan la participación ciudadana para incorporar los objetos museísticos en un mapa virtual, en el que los participantes pueden añadir materiales multimedia como textos, imágenes, vídeo o sonido, contar y compartir su opinión sobre lugares que conocen.

Historypin es el proyecto en el que la gente puede localizar fotografías en un mapa y otras personas pueden aportar más información a estas fotografías, puede ser considerado como una herramienta de crowdsourcing (FORSYTH, 2012). Esta iniciativa, nacida con el apoyo de Google en el año de 2011, consiste en una plataforma web y voluntarios de todo el planeta que participando en el proyecto y aportando contenidos diversos, mediante la digitalización de sus fotos, coleccionando y grabando historias sobre lugares, localizando y compartiendo contenidos relacionados con la historia de ciudades. Es una 
de las plataformas virtuales más grandes, permite acceder a 60.000 historias y 2.000 bibliotecas. Gracias a su uso fácil este proyecto ha tenido mucho éxito y el interés del auditorio global. Una de las potencialidades de este proyecto es la posibilidad de explorar la historia de la ciudad mediante diversas herramientas digitales como Google Maps, que localiza información, y Street View, que permite comparar vistas antiguas con actuales.

Otro proyecto similar creado para los usuarios que quieran compartir historias acerca de lugares de Dinamarca es la web 1001 stories of Denmark ${ }^{12}$. En este sitio, los usuarios pueden añadir información sobre sus lugares favoritos y comentar historias existentes, subir vídeos, imágenes, añadir etiquetas y participar en muchas otras actividades. En el mapa, se pueden agregar puntos y crear rutas temáticas. Además del mapa también se puede buscar información con la línea de tiempo.

Otro proyecto titulado London Street Views $1840^{13}$ tiene como objetivo crear un directorio de búsqueda de principios del Londres victoriano, que incluye las vistas de las calles de la ciudad.

El proyecto se basa en las guías ilustradas creadas, para las principales calles comerciales de Londres, por el editor John Tallis, para ayudar a los visitantes a orientarse más fácilmente en las confusas calles de aquella época. Cada uno de los 88 folletos tiene un plano con vistas de las calles elevadas, información sobre anuncios destacados, la historia de las calles y un directorio de empresas. Las vistas interactivas de las calles y plazas de la ciudad, creadas especialmente para este proyecto, permiten recorrer las calles de la

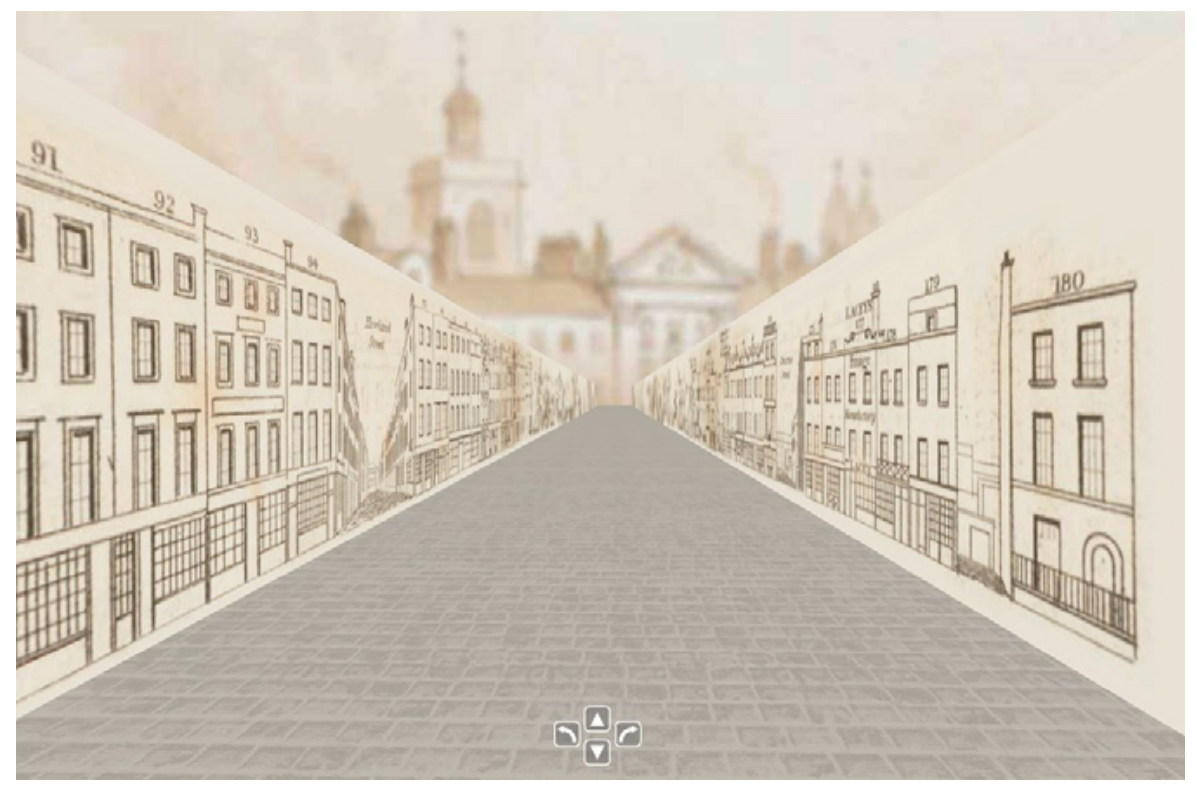

<http://www.kulturarv.dk/1001fortaellinger/ en_GB> [Consulta: 15/09/2015].

13

<http://crowd.museumoflondon.org.uk/lsv18 40/> [Consulta: 15/09/2015]. 
época victoriana de Londres, disfrutar de la imagen de sus fachadas y comparar las vistas históricas con las vistas actuales de las calles recreadas por Google Maps. Además de la lista de edificios que se pueden encontrar en la página principal, los folletos incluyen indicaciones e iconos fáciles de comprender y algunas recomendaciones que ayudan y facilitan la participación durante su desarrollo. Para contribuir al proyecto, el usuario debe registrarse en la web y rellenar el formulario que incluye información sobre el edificio, número de casa, calle y descripción general.

\section{CONCLUSIONES}

A la hora de elaborar este estudio hemos observado que el uso de la tecnología móvil en espacios urbanos está en la fase de crecimiento cuantitativo. Actualmente se están produciendo muchas aplicaciones de bajo coste con el uso de una tecnología de programación rápida y fácil. En la gran mayoría de casos, los contenidos de las aplicaciones (app) se diseñaron originariamente para otros soportes y posteriormente fueron reciclados y mal adaptados a las pantallas de un móvil o una tableta. Hoy en día, el objetivo prioritario de la mayoría de las entidades que desarrollan este tipo de productos es fomentar un producto aparentemente atractivo, de rápido consumo, para captar nuevas audiencias digitales.

En cuanto a las tendencias del uso de las tecnologías móviles en espacios urbanos, los resultados de este estudio demuestran que están presentes en el mercado de forma irregular. En casi todas las ciudades, las estrategias del modelo visita guiada toman la posición predominante con un 66\%; los modelos streetmuseum y juegos funcionan, de forma creciente, con un $16 \%$ y un $11 \%$, respectivamente, y las estrategias de carácter colaborativo tienen tan solo un $1,7 \%$.

El análisis realizado nos indica que el grupo de las estrategias basadas en el verbo informar (especialmente las propuestas de itinerarios pautados), que son la que encontramos con mayor presencia en el mercado actual, se caracterizan por una alta rigidez en el diseño de los recorridos, una pobreza considerable de contenidos y escasos elementos de interacción. Este grupo de aplicaciones ofrece pocas posibilidades para el diseño y desarrollo de herramientas interactivas, para la personalización de itinerarios y, además, no establecen puentes de colaboración entre los usuarios. Su mayor presencia en el mercado actual se explica porque presenta un modelo familiar tópico, al que están acostumbrados la mayoría de turistas. Su programación y ejecución, de muy bajo coste en comparación con los otros dos modelos, se realiza en un periodo de tiempo muy breve y resulta de fácil replicado y reproducción. El principal destinario de este tipo de estrategias es el turista que quiere visitar la ciudad en pocas horas que, al tener poco tiempo, nece- 
sita un producto que le ofrezca un itinerario pautado, ágil de consultar y fácil de recorrer. El criterio que sigue es ver el mayor número de monumentos y cuanto más rápido mejor. Por todo ello consideramos que el carácter informativo del primer grupo corresponde a un tipo de visita individual y superficial.

Los datos del análisis realizado revelan que el segundo y tercer grupo de estrategias (basados en los verbos jugar y construir), con una presencia menor en el mercado, son propuestas que buscan la calidad y la singularidad de la experiencia del visitante. Están dirigidas, en gran parte, al público local o al turista con un alto interés en cultura y patrimonio. Su principal objetivo es desarrollar contenidos y recursos que permiten conocer la ciudad de una manera distinta y entretenida. Por ello, estas estrategias incorporan todo tipo de tecnologías que les permiten enriquecer la experiencia del usuario in situ, potenciar la interactividad, y generar y añadir nuevos recursos y contenidos, creados por mismo el usuario. También proporcionan herramientas de intercambio de opiniones y permiten una mayor interconexión y colaboración entre usuarios, con lo que su consumo no caduca en pocas horas de la visita y puede prolongarse significativamente.

En nuestra opinión el modelo jugar es altamente recomendable para el sector turístico porque permite aprender y conocer ofertas de destino mediante pequeños juegos y experiencias lúdicas. Utilizar la "gamificación" es un recurso que, cada vez más, aporta un valor lúdico añadido a la experiencia. En lo referente a las estrategias que se basan en el verbo construir, del que existen pocos ejemplos, tienen un alto potencial para el desarrollo de estrategias lúdicas y de un alto carácter interactivo, especialmente para eventos, como ferias, festivales y celebraciones anuales. 


\section{BIBLIOGRAFÍA}

- AVOURIS, N.; YIANNOUTSOU, N. (2012) A Review of Mobile Location-based Games for Learning across Physical and Virtual Spaces. Journal of Universal Computer Science, 18(15), pp. 2120-2142

- BOYER, D.; MARCUS, J. (2011) Implementing mobile augmented reality applications for cultural institutions. En TRANT, J.; BEARMAN, D. (ed.) Museums and the Web 2011: Selected Papers from an international conference. Toronto Canada: Archives \& Museum Informatics, 2011 <http://www.museumsandtheweb.com/mw2011/papers/ implementing mobile augmented reality applicat.html> [Consulta: 25/07/2016]

- BRAZUELO, F.; GALLEGO, D. J. (2011) Mobile learning: los dispositivos móviles como recurso educativo. Alcalá de Guadaíra: MAD, 2011

- CARDONA, G.; FELIU, M. (2013) Redes sociales y museos. Cambios en la interacción cultural. HER\&MUS, Heritage and Museography, vol.V, n. ${ }^{\circ}$ 2, pp. 83-90

- COMA, L. (2013). Dinamizar y digitalizar la ciudad: itinerarios urbanos, dispositivos móviles y códigos QR. HER\&MUS. Heritage and Museography, vol. V, n. ${ }^{\circ}$ 2, pp. 63-68

- DAVIES, J. (2014) On-site Digital Heritage Interpretation: current uses and future possibilities at World Heritage Sites. Tesina de máster inédita. Reino Unido de Gran Bretaña e Irlanda del Norte: Durham University, 2014 <www. catedraunescoforum.upv.es/Thesis/2014DAVIES268 MACompleted_EN.pdf> [Consulta: 25/07/2016]

- FORSYTH, E. (2012) Learning through play: games and crowdsourcing for adult education. Australasian Public Libraries and Information Services, 2012, pp. 166-173

- GREVTSOVA, I. (2012) How to make urban archaeology understandable? Interpreting the heritage: from the stable panels to the new mobile devices. Proceedings of the 17th International Conference on Cultural Heritage and New Technologies <http://www.chnt.at/wp-content/uploads/eBo ok_CHNT17_Grevtsova.pdf> [Consulta: 25/07/2016]

- GREVTSOVA, I. (2013) El patrimonio urbano al alcance de la mano: arquitectura, urbanismo y apps. HER\&MUS, Heritage and Museography, vol. V, n. ${ }^{\circ}$ 2, pp. 36-43

- GREVTSOVA, I. (2014) Algunos ejemplos del uso de los códigos QR en el patrimonio urbano. En SANTACANA J.; COMA, L. (ed.) El m-learning y la educación patrimonial. Gijon: Trea, 2014, pp. 155-172

- GREVTSOVA, I. (2016) Interpretación del patrimonio urbano. Una propuesta didáctica para un contexto histórico mediante las aplicaciones de telefonía móvil. Tesis doctoral inédita. Universidad de Barcelona <http://www.tesisenred. net/handle/10803/347215> [Consulta: 22/07/2016]
- HARKEMA, C; NYGREN, C. (2012) Historypin for Library Image Collections: New Modes of Access for Unique Materials at the University of Saskatchewan Library. The Canadian Journal of Library and Information Practice and Research, vol 7, n. ${ }^{\circ}$ 2, $2012<$ http://synergies. lib.uoguelph.ca/index.php/perj/article/view/1970/2621\#. V5HXC0c3mUU> [Consulta: 22/07/2016]

- IBÁÑEZ ETXEBERRIA, A. (2011) Museos, redes sociales y tecnología 2.0. [Lejona, Vizcaya]: Servicio Editorial de la Universidad del País Vasco, 2011

- IBÁÑEZ ETXEBERRIA, A. et ál. (2014) Trends in the use of mobile technologies in Heritage Education in Spain. En AMOÊDA, R.; LIRA, S.; PINHEIRO, C. (ed.) Heritage 2014 - Proceedings of the 4th International Conference on Heritage and Sustainable Development. sl: Green Lines Institute, 2014, pp. 691- 699

- IBÁÑEZ ETXEBERRIA, A.; CORREA, J. M. (2004) Territorio, museo y nuevas tecnologías. Propuestas de desarrollo en Territorio Menosca. En VERA MUÑOZ, M. I.; PÉREZ PÉREZ, D. (ed.) Formación de la ciudadanía: las TICs y los nuevos problemas I XV Simposio Internacional de Didáctica de las Ciencias Sociales: Alicante (España), del 30 de marzo al 2 de abril de 2004 [recurso electrónico]. [Alicante]: Asociación Universitaria de Profesores de Didáctica de las Ciencias Sociales, [2004], pp. 131-138

- LAURILLARD, D. (2007) Pedagogical forms for mobile learning. En PACHLER, N. (ed.) Mobile Learning: towards a research agenda. London: Institute of Education University of London, 2007

- LÓPEZ BENITO, V. (2013) ¿Educar en el arte mediante Apps? Los museos de arte y el uso de aplicaciones móviles en el contexto español. Her\&Mus. Heritage and Museography, 2013, vol. V, n. ${ }^{\circ} 2$, pp. 69-74

- LÓPEZ BENITO, V. (2014) Estudio exploratorio sobre la interpretación didáctica del arte en el museo a través de tecnologías móviles. Tesis doctoral inédita. Universidad de Barcelona <http://www.tdx.cat/handle/10803/134505> [Consulta: 22/07/2016]

- LÓPEZ BENITO, V.; MARTÍNEZ T.; GREVTSOVA, I. (2015) El m-learning en la didáctica del patrimonio: ¿tendencias del nuevo milenio? Iber, n. ${ }^{\circ} 80$, julioseptiembre, 2015

- MITCHELL, C.; SUCHY, D. (2012) Developing Mobile Access to Digital Collections. D-Lib Magazine, 18, 1/2

- RIVERO, P. (2012) M-learning para la enseñanza del patrimonio en las salidas escolares. TOUR \& HER, Tourism and Heritage, 2012, vol. 1, n. ${ }^{\circ}$, pp. 56-62

- SALLÉS, N. (2013) Las apps y el aprendizaje de patrimonio basado en la indagación. Her\&Mus. Heritage and Museography, 2013, vol. V, n. ${ }^{\circ} 2$, pp. 91-97 
- SANTACANA, J.; COMA, L. (ed.) (2014) El m-learning y la educación patrimonial. Gijon: Trea, 2014

- SANTACANA MESTRE, J.; LÓPEZ BENITO, V. (coord.) (2014) Educación, tecnología digital y patrimonio cultural: para una educación inclusiva. Somonte-Cenero, Gijón: Trea, D.L. 2014 (Biblioteconomía y administración cultural; 273)

- SHARPLES, M.; TAYLOR, J.; VAVOULA, G. (2005) Towards a theory of mobile learning. En Mobile technology: The future of learning in your hands (Cape Town, South Afreica, 25-28 October, 2005). Papers <http://www. mlearn. org.za/CD/papers/Sharples.pdf> [Consulta: 22/07/2016]

- SHARPLES, M. (ed.) (2006) Big issues in mobile learning. Report of the workshop by the kaleidoscope network of excellence mobile learning initiative. Nottingham: LSRI. University of Nottingham, $2006<$ http://matchsz.inf. elte.hu/tt/docs/Sharples-20062.pdf> [Consulta: 22/07/2016]

- SHARPLES, M. et ál. (2009) Mobile Learning: Small Devices, Big Issues. En BALACHEFF, N.; LUDVIGSEN, S.; JONG, T.; et ál. (ed.) Technology-Enhanced Learning: Principles and Products. sl: Springer Netherlands, 2009, pp. 233-249

- SHARPLES, M. et ál. (2013) Innovating Pedagogy 2013: Open University Innovation Report 2: Exploring new forms of teaching, learning and assessment, to guide educators and policy makers. Milton Keynes: The Open University, 2013 <http://www.open.ac.uk/iet/main/sites/w ww.open. ac.uk.iet.main/files/files/ecms/web-content/Innovating_ Pedagogy_report_2013.pdf> [Consulta: 22/07/20 16]

- SINTORIS, C. et ál. (2013) Discovering the invisible city: Location-based games for learning in smart cities. Interaction Design and Architecture(s) Journal, 2013, n. ${ }^{\circ}$ 16, 2013

- STEAD, G. (2006) Mobile technologies: transforming the future of Learning: A look into the future of learning technologies. En Emerging technologies for learning. sl: Becta, $2006<$ http://www.mmiweb.org.uk/publications/ict/ emerging_tech01.pdf> [Consulta: 21/07/2016]

- VAN DIJK, D. (2011) Exploring Heritage in Participatory Culture: The MuseumApp. En TRANT, J.; BEARMAN, D. (ed.) Museums and the Web 2011: Proceedings. Toronto: Archives \& Museum Informatics <http://www. museumsandtheweb.com/mw2011/papers/exploring heritage_in_participatory_culture_th.html> [Consulta: $22 / \overline{0}$ 7/2016]

- VICENT, N. (2013) Evaluación de un programa de educación patrimonial basado en tecnología móvil. Tesis doctoral inédita. Universidad Autónoma de Madrid <https:// repositorio.uam.es/handle/10486/14321> [Consulta: 21/07 /2016] 